\title{
LA INVESTIGACIÓN COMO SUSTENTO DEL DESARROLLO
}

\author{
Guillermo Cuéllar-Barandiarán \\ Antropólogo, músico y cantautor, miembro del cuerpo de investigadores de \\ la Dirección Nacional de Investigaciones en Cultura y Arte de la Secretaría de \\ Cultura de la Presidencia de El Salvador. Graduado de la Maestría en Metodología \\ de la Investigación Científica de la Universidad Evangélica de El Salvador \\ 3.1416kin@gmail.com.
}

Recientemente se llevó a cabo en nuestro país el III Congreso Nacional de Educación Superior bajo el título: "La investigación como sustento del desarrollo", evento propulsado por el Ministerio de Educación (MINED) y el Consejo de Educación Superior (CES) ${ }^{1}$, con el apoyo de la Oficina de Crecimiento Económico de la Agencia de los Estados Unidos para el Desarrollo Internacional (USAID).

La asamblea que se reunió expresamente durante tres días, del 28 al 30 de abril del presente, contó con la participación de personeros de aproximadamente 40 entidades: Ministerio de Educación, universidades, asociaciones de profesionales, empresa privada, organismos de cooperación internacional y otras instancias vinculadas con la educación superior.

Según los patrocinadores, el Congreso pretendía "fomentar la Investigación Científica y Tecnológica y su interrelación con el mundo laboral, coordinadamente entre los actores principales de la Educación Superior, con el fin de apoyar a la construcción de la sociedad del conocimiento por medio de la creación de una Red Nacional de Investigación de Educación Superior."

Permítasenos a continuación compartir un sucinto análisis sobre ciertos puntos álgidos y algunas de las probables implicaciones que pudiesen desprenderse de tan importante cónclave.

Un primer aspecto a reflexionar sería si la dinámica que se desplegó durante los 3 días del Congreso logró rozar al menos las cuestiones centrales que se desprenden de los propósitos proclamados oficialmente:

1) ¿Cómo fomentar la investigación científica y la innovación tecnológica en nuestro país?

\footnotetext{
1 El Consejo de Educación Superior (CES) está conformado por: Universidad de El Salvador (UES), ITCA-FEPADE, Universidad Pedagógica (UPES), Universidad Evangélica (UEES), Universidad Salvadoreña Alberto Masferrer (USAM), Universidad Tecnológica (UTEC), Universidad Luterana (ULU), Universidad Católica de El Salvador (UNICAES), Escuela Mónica Herrera, la Asociación Nacional de la Empresa Privada (ANEP) por medio de la ASI, el MINED y el Consejo de Asociaciones de Profesionales de El Salvador (CAPES).

2 https://www.mined.gob.sv/index.php/ints/item/7495-tercer-congreso-nacional-de-educaci\%C3\%B3n-superior.html
} 
2) ¿Cómo interrelacionar estos quehaceres académicos con el mundo laboral en nuestro país?

3) ¿Cómo habrán de interactuar los principales actores (Estado, universidades, empresa privada, gremios y organismos de profesionales investigadores) que lidiarán con estos imponentes desafíos en nuestro país?

Un segundo nivel de análisis podría orientarse a establecer los énfasis que se expresaron en el Congreso. Algunos de éstos pueden distinguirse entre líneas, a partir de las temáticas programadas en las conferencias, paneles, presentaciones de proyectos, conversatorios.

Por ejemplo, un énfasis llamativo sería el hecho de que la temática relativa a la cooperación entre empresa privada y universidades para el impulso de proyectos, fue desarrollada exclusivamente en las conferencias de los invitados internacionales. Sumado a ello, el único conversatorio programado en el Congreso fue con dichos expositores internacionales, y el tema que se discutió con ellos fue: "Impacto del Asocio Universidad-Empresa sobre el diseño de Políticas de Educación Superior".

Por contraste, entonces, se revela un vacío en las exposiciones nacionales con respecto a este importante tópico, el cual podría obedecer a que en nuestro medio existe inexperiencia, descoordinación o peor aún: divorcio entre la gran empresa y los institutos universitarios con respecto al tema de la investigación científica.

Uno podría decantarse por la impresión más negativa que sugiere esta cuestión, cuando se observan los títulos de los proyectos de investigación que fueron presentados durante el Congreso.

Los 6 proyectos de investigación que presentaron 9 institutos de educación superior acometen problemas propios de la productividad primaria (agricultura e industria), de la salud pública, de la educación y de la vivienda, los cuales, todos ellos, están vinculados a la gestión estatal. Mientras tanto, la gran empresa en nuestro país (ANEP-ASI-Cámara de Comercio), al menos en las tres últimas décadas, se sabe que ha venido orientando su estrategia de macro inversión hacia sectores terciarios de la economía (comercio/servicios).

Dada esta premisa, tendría cierta lógica lo que pudiese estar ocurriendo en cuanto al tipo de relación entre los protagonistas que intervienen en la praxis de la investigación científica en nuestro país: una conexión entre el Estado y la institucionalidad universitaria, y un desencuentro de la empresa privada con los primeros.

Un último punto de reflexión lo dedicamos al debate que de alguna manera se ha abierto en el ámbito escolástico local, sobre esta gran temática de la investigación científica al servicio del desarrollo.

Días después del evento que nos ocupa, el Foro de Intelectuales de El Salvador (FIES) y la Asociación Salvadoreña de Sociólogos y Sociólogas (ASS) se hicieron eco de ciertas "críticas al desempeño de las universidades en el campo de la investigación científica y tecnológica”, críticas que uno de los panelistas invitados 
al Congreso logró expresar durante su intervención, la cual, según varios de los asistentes, resultó "bastante subida de tono, aunque todo lo que dijo era cierto".

A continuación, reproducimos la síntesis del polémico planteamiento que han avalado y divulgado en sendos comunicados las antedichas asociaciones de profesionales:

“a) El estado de la investigación científica en El Salvador es endeble porque no tiene incidencia en el crecimiento económico y el desarrollo social del país.

b) En el país no existe una política de Estado para promover y desarrollar la investigación científica, sumada a la incapacidad del MINED para auditar y establecer controles de calidad en la educación.

c) El principal obstáculo de la investigación científica en El Salvador es la falta de interés de las mismas universidades."

Aunque pueda reconocerse que tales señalamientos albergan cierta dosis de verdad, algunos argumentos pueden relativizarse:

1. Uno de los puntos cuestionables en este planteamiento es su enfoque segregacionista. Es decir, la lógica de la crítica individualiza y descontextualiza a unos protagonistas, sin observarlos al interior de una sinergia imprescindible, donde otros actores habrán de intervenir de manera simultánea y decidida en el proceso.

Ya antes hemos señalado la posibilidad de una descoordinación entre actores primordiales que intervienen en el impulso de la investigación científica en el país - universidades y empresa- debido a opciones contrapuestas: La cúpula de la gran empresa no está orientada hacia sectores primarios de la economía, mientras que las universidades han proseguido en gran medida por este camino.

Este desencuentro pudiese estar impidiendo una colaboración más comprometida entre ambos actores en proyectos de largo alcance.

Bajo estas circunstancias, sería entonces explicable que desde los campus universitarios se albergarse una impresión de lasitud en el impulso de proyectos relevantes, sobre todo en lo que respecta al apoyo financiero que estos proyectos ciertamente requieren.

2. Sin duda que la investigación científica en nuestro país se encuentra aún en ciernes en muchos aspectos. No obstante, para explicar esta impúber condición no puede aceptarse el vago argumento de una "falta de interés de las mismas universidades".

Es un hecho que las universidades que funcionan en el país se han visto impelidas en las últimas décadas a erigir una institucionalidad investigativa, en la medida en que este tema representa un requisito de acreditación ante el organismo rector de la educación superior. ¿Cómo entonces no van a estar interesadas en el quehacer investigativo? No obstante, el mero cumplimiento de un requisito de acreditación 
puede actuar en menoscabo de una dinámica de crecimiento sostenido de dicha institucionalidad.

En este sentido, valdría la pena que los institutos de educación superior, con la mano en la conciencia y la frente en alto, pudiesen dilucidar ciertos puntos claves al respecto:

¿Qué porcentaje de su presupuesto anual están dedicando a la investigación científica? ¿Existe una relación justa entre su inversión en infraestructura y su inversión en incremento de la investigación científica? ¿Con cuántos investigadores de planta cuentan sus institutos de investigación? ¿Tal número guarda una relación justa con el crecimiento de la población estudiantil que verifica la institución? ¿Cuánto de su presupuesto dedican a la superación de sus investigadores de planta en áreas de post-grado (maestrías, doctorados, post-doctorados)? ¿Qué áreas de posgrado enfatizan: áreas de productividad primaria, secundaria, terciaria? ¿Qué horizonte están divisando a la hora de lanzarse a proyectos concretos: problemáticas coyunturales (como el marketing político, por ejemplo) o problemáticas de largo alcance de carácter económico, social y ambiental? 